\title{
The Removal of Charges for Health Services in the Jamaican Public Health System: Impact on the Health Practitioners' Performance
}

\author{
Adella Campbell $^{1, *}$, Vanesa M. Tennant ${ }^{2}$, Fitzroy Henry ${ }^{3}$ \\ ${ }^{1}$ Caribbean School of Nursing, University of Technology, Jamaica \\ ${ }^{2}$ Independent Researcher, Jamaica \\ ${ }^{3}$ College of Health Sciences; University of Technology, Jamaica
}

Copyright $(2019$ by authors, all rights reserved. Authors agree that this article remains permanently open access under the terms of the Creative Commons Attribution License 4.0 International License

\begin{abstract}
There is an ongoing discussion between governments, international agencies, and advocacy groups on whether user fees imposed at government health facilities in poor countries should be removed. Proponents argue that abolition of charges would lead to greater access for the poor, therefore offering the underserved the opportunity to access health services. There are limited studies that examined how health practitioners, an important stakeholder are affected. This research examined the impact of the 2008 removal of charges for health services on health practitioners in Jamaica. Using a mixed method evaluation design, we found that main health practitioners - nurses, doctors and pharmacists were not satisfied with the policy change. When compared to that before removal of charges, $10 \%$ less practitioners felt that performance on the job was good. Health practitioners alluded to increased workload, negative effects on their physical and emotional status and dissatisfaction with their work environment. Other problems encountered by health practitioners included unavailability of resources, shortage of staff, lack of equipment and lack of administrative support. The lesson learned for policymakers is that the critical problems identified will eventually outweigh the substantial health gains if adequate resources (financial and human), administrative support as well as improved service management are not soon injected into the public health system.
\end{abstract}

Keywords User Fees, Removal, Abolition, Health Practitioners, Jamaica

\section{Introduction}

Individuals have good access to health services when they receive the right service, at the right time, in the right place [1]. For many people, however, poor access to health services is a reality. Furthermore, such poor access appears to be a global issue, regardless of the type of health care system that exists in any country. Diverse factors, such as an individual's socioeconomic status, ethnicity and gender contribute to the inability to access health care. In addition, charges for health care (user fees) are major barriers to access health services when required $[2,3]$.

One solution adopted by some policymakers for the problem of poor access, as well as to ensure universal coverage, is the abolition of user fees [4]. Removal of user fees has been shown in many countries to be effective in achieving improved access to health services $[5,6]$.

Specifically, the impact of user fees removal on health workers varies. For example, in Africa, some health workers supported the policy [6]. Some health workers welcomed the abolition of fees, particularly because they eliminate cost-recovery difficulties [6]. While in some instances, it was unpopular among others [7]. Other health care workers felt a sense of being exploited, overworked and demotivated to the point of considering resignation. In addition, ambivalence was evident among some health workers in some countries who, on the one hand, expressed being motivated professionally by their ability to assist with improving the health of people, but on the other hand, were dissatisfied with the poor uptake of the services provided and the effects on their work.

Health worker recruitment, retention, distribution and performance were critical factors affecting the performance of a health system [8]. There is a research gap on the impact of fee exemption policies on health $[8,9]$. Most of the studies have focused on regions in Africa, and this study focuses on an understudied region, of the Caribbean. This research will seek to add to the body of literature, by examining the case of Jamaica, where user fees were abolished in the public health sector in 2007 for children under 18 years and in 2008 free health care was 
introduced for all users of the public health system. The study will discuss the impact of the removal of charges for health services, in Jamaica, on health practitioners.

\section{Methodology}

\subsection{Jamaica: Removal of Charges for Health Services}

Jamaica has a population of approximately 2.8 million and is a Caribbean small island developing state. In Jamaica, the fee payment system was deemed as oppressive for some users, especially the poor, who did not utilize the services although there was a need [10]. This served as impetus for the removal of user fees. On May 28, 2007 user fees were abolished for children under the age of 18 years, and on April 1, 2008 for services in the public health system generally. Under this new arrangement, health services at the 23 public hospitals and over 313 health centres were provided without charges to the users. The free services included but were not limited to: registration, doctor's examination, hospital stay, diagnostic services (x-rays and laboratory tests of various kinds), drugs, physiotherapy, surgeries, family planning, immunization, antenatal care, renal dialysis, drugs for chemotherapy, radiation therapy, certain high cost diagnostic services such as MRI [and] certain high cost appliances [11].

Fees were retained by the public health system for several services. These included fees paid by private patients (persons with insurance and non-residents); fees for morgue services except for specific cases; medical examinations and reports obtained from Primary Health Care (PHC) for business use; food handlers 'fees; and medications and drugs for international travel [11].

\subsection{Research Design}

A mixed method approach of qualitative and quantitative design was used. Data was collected from all four (4) Regional Health Authorities (RHAs), which are defined by geographical boundaries, and have overarching responsibility for several parishes in Jamaica. Through RHA, public health care is provided through a network of primary, secondary and tertiary health care facilities. Data was collected in 2016, after the removal of user charges.

Focus group discussion were conducted among a purposive sample of main health practitioners (physicians $[\mathrm{n}=10]$, nurses $[\mathrm{n}=30]$ and pharmacists $[\mathrm{n}=20])$. Inclusion criteria for health practitioners included those who were in the system before the policy change to present. Representations were from all four RHAs and also from the various levels within the health system. Questions included (i) their role in the implementation of the user fee policy; (ii) changes in their work since the new policy; (iii) current quality and effectiveness of care; (iv) their contribution to improving access to health services; (v) their experience with funding with resources, and (vi) their general impression of the expectations and implications of the policy change before, immediately after and currently. Thematic Analysis was used to analyze classifications and present themes (patterns) that relate to the data [24]. Transcribed interviews were analyzed to extract themes relating to impact on health practitioners.

A quantitative approach was used, with health workers who participated in a questionnaire survey. This was to determine their views on affordability of services and available resources, including manpower, materials such as medical equipment and funding of the health. Key analyses compared health utilization rates before the user fees policy, immediately after and currently. The integration of quantitative and qualitative data provides critical insights into not only the impact, but importantly, the reasons thereof.

\section{Results}

\subsection{Health Professional Survey}

\subsubsection{Health Practitioners Satisfaction}

The findings revealed that some health practitioners (31\%) were satisfied before the removal of the user, however dissatisfaction was higher with the removal of user fees (52\%) at the point of data collection in 2016. Therefore, it is suggested that health practitioners' satisfaction decreased with the removal of user charges. See Figure 1. 


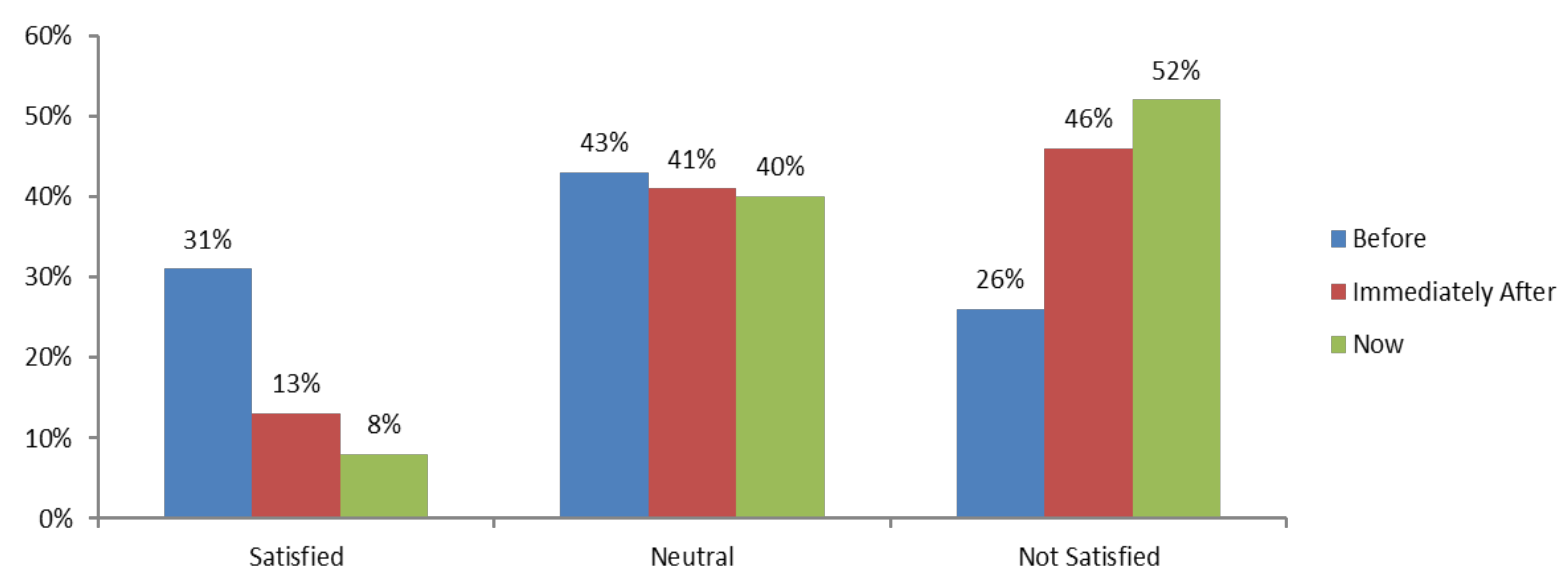

Figure 1. Health Practitioners Satisfaction Level

\subsubsection{Effect on Job Performance}

The health practitioners rated their job performance as good, both before and after the implementation of the removal of charges, with $78 \%$ and $68 \%$ respectively. See Figure 2

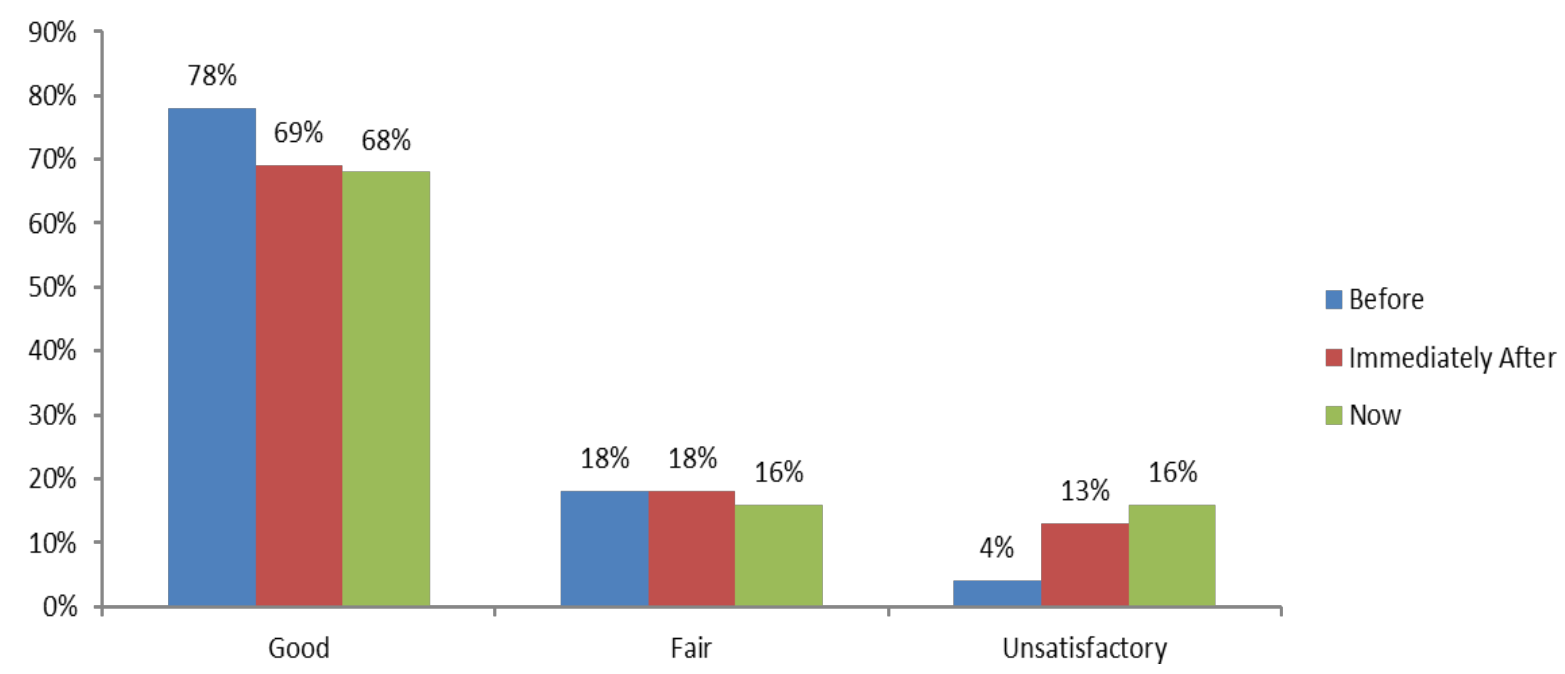

Figure 2. Effect on Health Practitioners' Job Performance

\subsubsection{Effects on Workload}

Prior to the removal of charges, majority of the health practitioners (50\%) indicated that they were satisfied with their workload. This changed after the removal, with $55 \%$, indicating dissatisfaction presently, and $40 \%$ were both neutral and dissatisfied immediately after the removal. See Figure 3

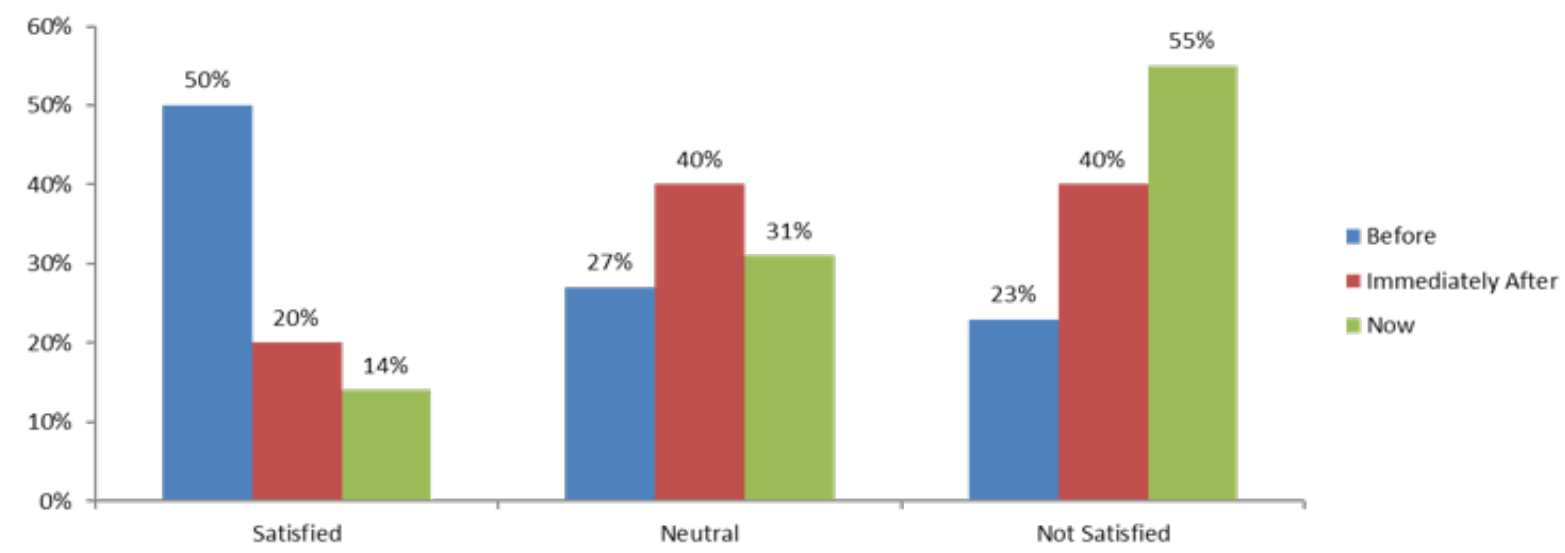

Figure 3. Effect on Health Practitioners' Workload 


\subsubsection{Effect on Work Environment}

Before the removal of the user charges, health practitioners $(50 \%)$ were satisfied with their work environment. However, after the removal, most (55\%) were currently dissatisfied with their work environment. See Figure 4.

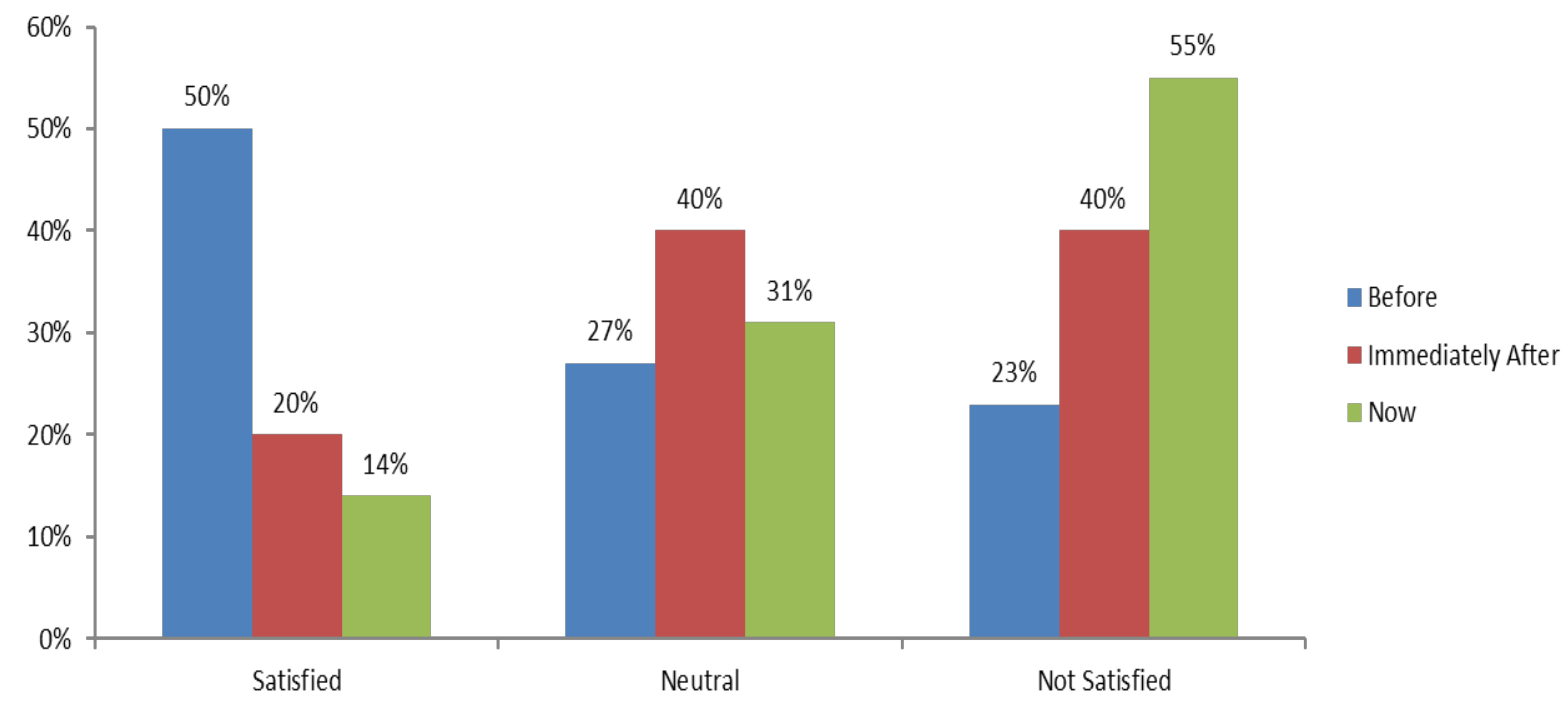

Figure 4. Effect on Work Environment

\subsubsection{Effect on Availability of Resources}

Prior to the removal of the user fee policy, majority (52\%) believed that the resources available were fair. Immediately after the removal of charges, most still deemed resource availability as fair (54\%), however at present, most (49\%) deemed it as poor. See Figure 5.

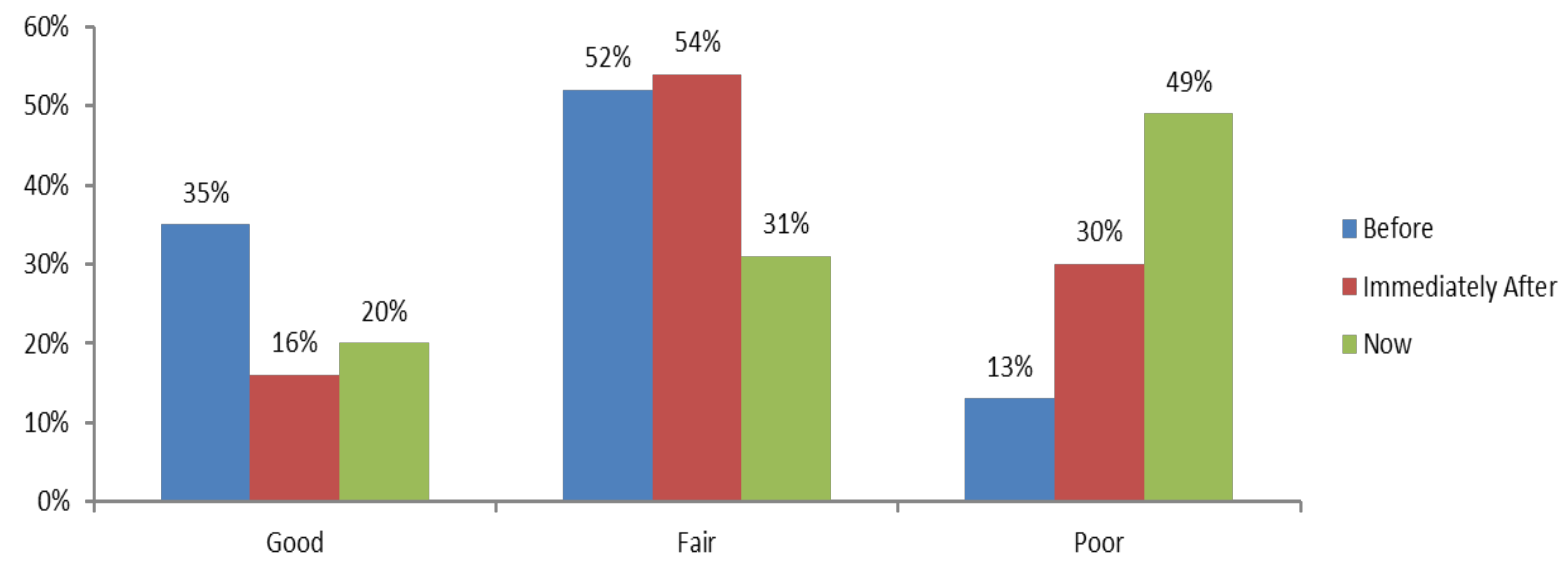

Figure 5. Effect on Availability of Resources

\subsubsection{Effect on Quality of Care}

Before the removal of user fee, the majority of health practitioners $(76 \%)$ deemed the quality of care as good. This view changed after the removal, with quality of care seen as 'fair' immediately after (47\%) and thereafter. See Figure 6. 


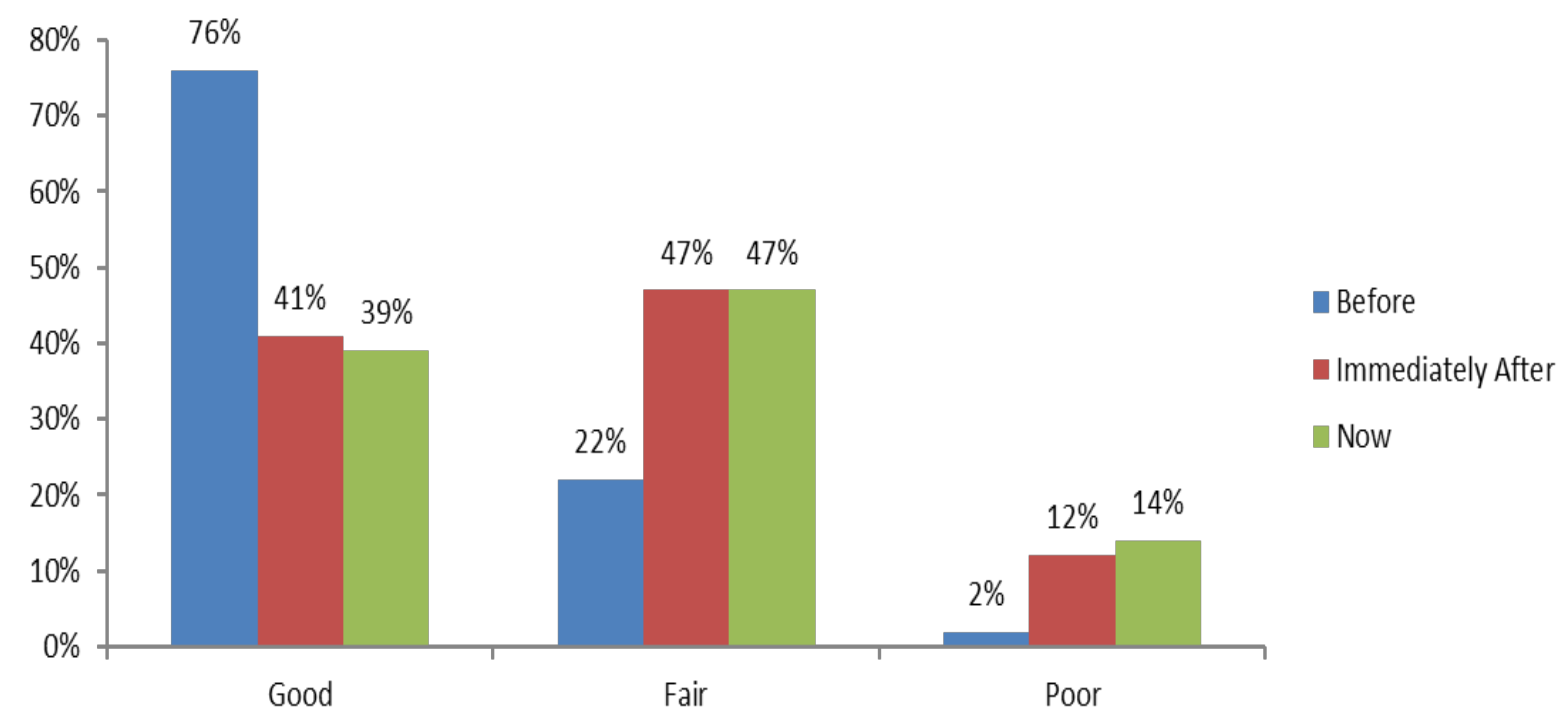

Figure 6. Effect on Work Environment

\subsubsection{Factors Impacting Health Practitioners' Satisfaction with Policy}

Multiple regressions were conducted to examine the factors that impacted Health Practitioners satisfaction with the new policy. To conduct this investigation, the independent variables explored were satisfaction with work environment, availability and quality of resources and quality of care patients receive. The overall model explained 39.1 percent of variance in satisfaction with new policy $(\mathrm{R}$ square $=.391)$, which was revealed to be statistically significant, with a $p$-value of $0.000, \mathrm{p}<.05$. (See Table 1 and Table 2 )

An inspection of individual predictors revealed that satisfaction with work environment ( $p$ value of $, 001, p<.05$ ) was the significant predictors of satisfaction with new policy. Therefore, higher levels of satisfaction with work environment are associated with higher levels of overall satisfaction with the new health policy (See Table 3) destination, and U.S tourists reported significantly more overall satisfaction than did European tourists.

Table 1. Model Summary

\begin{tabular}{|c|c|c|c|c|}
\hline Model & $\mathrm{R}$ & R Square & Adjusted R Square & Std. Error of the Estimate \\
\hline 1 & $.626^{\mathrm{a}}$ & .391 & .344 & .74717 \\
\hline
\end{tabular}

a. Predictors: (Constant), Quality of personal care received, Availability and quality of resources in the work environment, Satisfied with work environment

Table 2. ANOVA Results

\begin{tabular}{|c|l|c|c|c|c|c|}
\hline \multicolumn{2}{|c|}{ Model } & Sum of Squares & df & Mean Square & F & Sig. \\
\hline \multirow{3}{*}{1} & Regression & 13.995 & 3 & 4.665 & 8.356 & $.000^{\text {b }}$ \\
\cline { 2 - 8 } & Residual & 21.772 & 39 & .558 & & \\
\cline { 2 - 8 } & Total & 35.767 & 42 & & & \\
\hline
\end{tabular}

a. Dependent Variable: Satisfied are with the new policy

b. Predictors: (Constant), Quality of personal care received, Availability and quality of resources in the work environment, Satisfied with work environment

Table 3. Model Coefficients

\begin{tabular}{|c|c|c|c|c|c|c|}
\hline & \multirow{2}{*}{ Model } & \multicolumn{2}{|c|}{ Unstandardized Coefficients } & \multirow{2}{*}{$\begin{array}{c}\text { Standardized Coefficients } \\
\text { Beta }\end{array}$} & \multirow{2}{*}{$\mathrm{t}$} & \multirow{2}{*}{ Sig. } \\
\hline & & B & Std. Error & & & \\
\hline \multirow{4}{*}{1} & (Constant) & 1.337 & .506 & & 2.641 & .012 \\
\hline & $\begin{array}{l}\text { Satisfied with you work } \\
\text { environment }\end{array}$ & .488 & .134 & .520 & 3.633 & .001 \\
\hline & $\begin{array}{l}\text { Availability and quality of } \\
\text { resources in the work } \\
\text { environment }\end{array}$ & .203 & .120 & .241 & 1.693 & .098 \\
\hline & $\begin{array}{l}\text { Quality of personal care } \\
\text { received - Now }\end{array}$ & -.043 & .163 & -.039 & -.261 & .795 \\
\hline
\end{tabular}

a. Dependent Variable: Satisfaction with the new policy 


\subsection{Focus Groups \& Interviews}

The qualitative analysis focused on the impact of abolition/removal of charges on health practitioners. Using an exploratory approach, the main themes that emerged, which highlighted the way in which health practitioners were impacted were: increase in workload, increased stress, increasing expectations from patients, scarce resources.

\subsubsection{Increase in Workload}

In the interview, and focus group discussions, health practitioners shared that they experienced increase in workload after the removal of charges and noted an increase in the number of patients daily to both clinics and hospitals.

"Since the introduction we've had an increased workload... We've had a great, or we had a larger patient load than it was before" [Nurse]

"With the introduction of free healthcare more patients came to the hospital and more patients came to the clinics. So, you had a greater workload." [Doctor]

\subsubsection{Increased Stress}

Based on the demand and the fact that there were limited resources the medical practitioners all highlighted that they were fatigue and overwhelmed and had so much stress after the implementation of the no user fee. They felt mentally unstable at times as the setting was chaotic and discouraging.

"...you were more fatigued at the end of the work day. You were more easily overwhelmed. The ability to manage the level of stress was more of a challenge. There were more patients, so more work, same amount of staff members. You get tired more easily at the end of the day." [Doctor]

"...it has become more strenuous on the staff and also on the whole healthcare system, on the facility itself right. ... And, of course, it's not only that the staff are being working harder, more tired, more stressful but of course the mental strains that is put on the staff at this time and it is sometimes very discouraging." [Nurse] "... a lot more work, less hands, frustrated staff, people were called upon to do more with little, it was just a chaotic, demotivated that let the staff burn out and just general frustration .... I mean patients were coming from all over the region ..." [Doctor]

...the patient load increased probably by $100 \%$....[Pharmacist]

\subsubsection{Increased Expectations from Patient}

The interviewees posited that with the implementation of the policy of free health care, the expectations of their patients increased dramatically. It was revealed that in some instances, patients abused the system, visiting the health care facility daily with their own demands, and. not wanting to follow the waiting procedures as they did prior to removal of user charges, with patients feeling entitled to anything upon request.

"I think the demand on us increased in that patient's expectation. They're expecting more, or you had a greater influx of patients and the expectation of the patients are that they are to get everything, now the government says it's free and we're to get this or that. ..." [Nurse]

"At the time when free health care was implemented, it greatly impacted all of us. Everything was free. The patients decided that well. They came in the doors and thought that with everything being free then there had keys to the kingdom which we speak and we had like a larger work load coming in and of course less resources to go around because we had a higher volume of patients using up the same amount of resources then do the Math" [Doctor]

"..we found that the expectations of patients heightened, because they expected to get through early, they don't want to wait and everything should be available for them. It is a lot more pressure." [Nurse]

\subsubsection{Scarcity of Resources}

Health Practitioners shared that with the implementation of the no user fee policy; there was a resulting limited supply of resources to meet the influx of patients. There were monetary restraints as it relates to availability of petty cash to carry out daily obligations with ease. Also, it was noted that there has been shortage in staff. This led to back-lag of critical details such as blood work and shortage of medication. The environment became in conducive to offer productive medical attention.

"..you have limitations in the provision of supplies. Before, persons would end up with petty cash and you could buy items and you could basically use the petty cash to your disposal sometimes. But, with the removal of user fees, we did not have access to petty cash, so basically if you don't have it, we don't have it and then that was the limitation in the provision of services to the patients. But as a professional you know you would still carry out your duties based on the resources you had to work with." [Nurse]

“... work is significantly affected, we didn't have enough resources, the number of patients increased significantly, and we don't have enough staffing. There is nobody to assist in the clinics. We don't have the lab works available to see the patients. We don't have the resources to like high need medications, high need phalanges, page on call staff, on calls, enough chairs and tables, no appliance, no air condition, such kind of things." [Doctor]

"...sometimes not enough supplies to work with, sometimes not enough drugs available as well" [Pharmacist] 


\subsubsection{Quality of Care}

In the focus group and interview, health practitioners highlighted that the quality of care provided to patients decreased, with longer waiting hours, less time spent with patients

"Overcrowded situations, patients waited long hours; they were there long before pharmacy opened and there was no guarantee that they would get through" [Pharmacist]

I'll say because of the change in this process the time frame to give our service or adequate service to the client, it is depleted or not done on time.. the time is not well spent on the patient how you want the care to be provided. Each patient is not satisfied then at the end of each care given" [Nurse]

"We don't have the lab works available to see the patients. We don't have the resources to like high need medications, high need phalanges, page on call staff, on calls, enough chairs and tables, no appliance, no air condition," [Doctor]

\section{Discussion}

Jamaica introduced free health services, through the removal of user fees/ charges for all users of the public health system. The intentions of these policy interventions were to improve access to health care for poor Jamaicans, to reduce inequity in accessing health services, to reorient the public health system to reflect a primary care focus, to enhance staff efficiency by providing the right skill mix for service delivery; and to find suitable financing and service delivery mechanisms [11].

Through survey, in-depth interviews and focus groups, this research explored the removal of Charges for Health Services in the Jamaican Public Health System, specifically the impact on the Health Practitioners' Performance. This study is relevant, given limited studies on the impact of fee removal on health practitioners $[8,12]$.

The findings of this research suggested that removal of the fees, had unintended consequences and/or impact on health practitioners. In general, health practitioners- nurses, doctors and pharmacist - pointed to perceived negative influences of removal of the user fee on their work environment and were generally dissatisfied with experiences in the workplace that were effects of or exacerbated by the policy change - lower levels of satisfaction, reduced job performance, higher workload, scarcity of resources, reduction in the quality of care offered to patients. The regression analysis revealed that work environment was the significant predictor, which may suggest that maintaining or enriching the work environment in which Health Practitioners operate is important to the successful implementation of no-user fees policy.

It was shared that patient utilization of the public health system increased exponentially following the abolition of user fees, and likewise patient demand. The work of health practitioners was affected as they had to provide the expected and required services to the patients despite an increase in workload and constraints such as inadequate resources. Health practitioners painted a picture where they were stressed and over stretched. It was highlighted that in some instances, patients visited repeatedly to seek free drugs and other health services.

Health practitioners generally found their work was more stressful following the policy change. The impact of the policy resulted in an exponential increase in workload, which had implications for how services were delivered and the satisfactory outcome of the policy. The quality of care in relation to waiting times, drug availability and resources was argued as being negatively affected. Also, the increased patient load meant less time spent assessing patients. This negatively affected health practitioner's ability to maintain the standards required to provide quality care. The findings align with other studies such as [8], [12] and [13].

Practitioners embraced the policy change however, even with the negative impact on their work environment. Of note, is that during the focus group and interview discussions, health participants shared discontentment about the lack of their involvement in the process, with participants echoing that there was no or limited consultation with health practitioners and felt that removal of user fees had political agenda.

"We had no role in the policy process it's something that we heard it on the airwaves that this would have been done as an election promise and after the election the promise was fulfilled, and this was done so we had nothing to say or do about it" [Nurse]

There was no consultation with us as doctors in the health system that I know of. I was not called to any meeting, we just heard that this was being done and it was done [Doctor]

"Well, in terms of roles during the abolition of user fees the healthcare worker did not have a role in the policy implementation or the plan to remove user fee. The government of the day made a promise; a political promise to the populous of Jamaica and being elected, the government of today, then they fulfilled their promise [Pharmacist]

Health Practitioners noted some recommendations or actions that the government could undertake, which may result in a better work environment. Similar sentiments were shared by multiple practitioners.

One recommendation was limiting the removal of charges to children and older persons (e.g. under 18 and over 65 years), or creating a system that filters and identifies persons that can afford, "...they [the government] have to separate the patients who can afford, who cannot afford, who are really poor and then they can give them some kind of card or something, so that the very poor 
people can still access, people who are rich can pay". A second recommendation was a more thorough assessment by the government on the full cost of removing user fees, including how to sustain resources, “... idea of health care being free is good ... but what we need to look at is at the affordability to the government and the facility. Can we really manage it? So, whereas the whole idea is welcomed can we manage it. So, I think that what we really need is proper assessment and proper decisions, proper implementations of policies and such". Third and final recommendation was greater public awareness and education for patients, so that they are clearer on what the free policy covers. Nurses shared instances where persons had a private health insurance but opted not to use it during their visit, which should not be the case. Another example provided was where patients demand free soap, tissue, sanitary napkin inter alia stating that everything is free.

\section{Conclusions}

Ultimately, the policy change was not just a political rhetoric because it addressed a need that existed. Increased utilization of health services was achieved, despite inferences that user fees may just be one of the problems encountered by users of the health system. However, the policy change had serious implications for budgetary allocation, resource allocation, and human resources, Inadequate funding, limited resources, lack of additional incentives for increased workload were undermining the policy. Policymakers should be cognizant that the critical problems identified will eventually outweigh the substantial health gains if adequate resources (financial and human), administrative support as well as improved service management are injected into the public health system

These problems could have been averted or minimized, if careful analysis had been undertaken prior to its implementation, and greater involvement of health practitioners in the process.

\section{REFERENCES}

[1] J.L Chapman, A, Zechel. Y.H, Carter, S. Abbott. Systematic review of recent innovations in service provision to improve access to primary care. Br J Gen Pract, Vol. 54, No. 2, 374-381, 2004

[2] S. N. Kiwanuka, E.K. Ekirapa, S. Peterson, O. Okui, M. Hafizur Rahman, D. Peters, G.W Pariyo,. Access to and utilisation of health services for the poor in Uganda: A systematic review of available evidence. Royal Society of Tropical Medicine and Hygiene, 102, .2008

[3] T. Yamada, C.C, Chen, T. Yamada, I.M. Chiu, J. Smith. Healthcare services accessibility of children in the USA. Applied Economics, Vol. 41, No. 4, 2009
[4] V. Ridde, A. Diarra, A. A process evaluation of user fees abolition for pregnant women and children under five years in two districts in Niger (West Africa). Biomedical Central Health Services Research, Vol 9, No. 89, 2009

[5] V. Ridde. F. Morestin. A scoping review of the literature on the abolition of user fees in health care services in Africa. Health policy and planning, Vol. 26, No. 1, 2010

[6] S. Witter, D.K Arhinful, A. Kusi, S. Zakariah-Akoto. The experience of Ghana in implementing a user fee exemption policy to provide free delivery care. Reproductive Health Matters, Vol. 15 No. 30, 61-71. 2007

[7] J. Chuma, J. Musimbi, V. Okungu, C. Goodman, C. Molyneux, C... Reducing user fees for primary health care in Kenya: Policy on paper or policy in practice? International Journal for Equity in Health, Vol. 8, No. 1, 2009

[8] S. Witter, H, Wurie, M.P Bertone. The free health care initiative: how has it affected health workers in Sierra Leone? Health policy and planning, Vol. 31, No. 1, 1-9, 2016

[9] B. McPake, S. Witter, T. Ensor, S. Fustukian, D. Newlands, T. Martineau, Y. Chirwa, Y. Removing financial barriers to access reproductive, maternal and newborn health services: the challenges and policy implications for human resources for health. Human Resources for Health, Vol. 11, No.1, 2013

[10] PIOJ \& STATIN. Jamaica survey of living conditions 2007. Kingston, Jamaica, 2008

[11] MOH. Statement on abolition of user fees in public health facilities. [News release]. Kingston, Jamaica, 2008

[12] A. Lépine, M. Lagarde, A. Le Nestour. How effective and fair is user fee removal? Evidence from Zambia using a pooled synthetic control. Health economics, Vol. 27, No. 3, 493-508, 2018

[13] K. Van der Veken, F. Dkhimi, B. Marchal, P. Decat, They Are after Quantity, Not Quality: Health Providers' Perceptions of Fee Exemption Policies in Morocco. International journal of health policy and management, Vol. 7. No. 12,2018 